\title{
Influence of tourist activity on the diversity of seaweed from reefs in Maracajaú, Atlantic Ocean, Northeast Brazil
}

\author{
Ingrid B. Silva, ${ }^{1}$ Mutue T. Fujii, ${ }^{2}$ Eliane Marinho-Soriano ${ }^{*}, 1$ \\ ${ }^{1}$ Departamento de Oceanografia e Limnologia, Universidade Federal do Rio \\ Grande do Norte, Brazil, \\ ${ }^{2}$ Instituto de Botânica, São Paulo-SP, Brazil.
}

Revista Brasileira de Farmacognosia Brazilian Journal of Pharmacognosy 22(4): 889-893, Jul./Aug. 2012

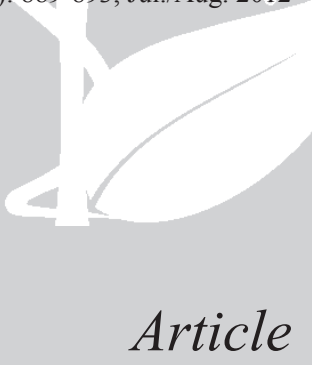

Article

Received 01 Nov 2011

Accepted 12 Jan 2012

Available online 5 Jun 2012

Keywords: reef environment macroalgae diversity tourism

ISSN 0102-695X http://dx.doi.org/10.1590/S0102695X2012005000078

\section{Introduction}

Seaweeds are considered to be important ecological and economic components of marine ecosystems around the world. They occupy a variety of habitats usually fixed upon a hard (organic or inorganic) substrate, including reefs, rocky shores, mangrove roots, sea grass meadows, and, less commonly, growing fixed on sandy bottoms or even free floating. Algae are organisms of great significance in reef environments and are present in diverse conditions, carrying out several functions. These include primary production, construction and cementation of reefs, as well as facilitating the establishment of coral and formation of habitats for other species. Despite their ecological benefits, they can also contribute to degradation in coral reefs, particularly in "phase shift" where coral species are replaced by seaweed species (McCook, 1999).

Natural and anthropogenic disturbances can cause one dominant organism to replace another (Petraitis \& Dudgeon, 2004). These changes in natural communities can affect the flow of energy, abundance and diversity of the native community and valuable services to human society (Sousa, 1984; Pickett \& White, 1985). Reduction in herbivores due to overfishing and an increase in nutrient and sediment loads are contributing factors in this process.
Healthy reef environments provide significant economic and ecological benefits to coastal communities, including fishing, protection from coastal erosion, food and tourism. The wide biological diversity of these environments is also being explored for bioactive compounds used in drug manufacturing. Despite their obvious value to humans, most coral reefs around the world are endangered or have already been destroyed by human activities (Bryant et al., 1998).

The effect of increased tourist and recreational activities on reef areas has been cause for concern with regard to balance in these environments. Recreational marine activities affect corals in many ways, such as trampling, breakages, physical contact with organisms, sediment resuspension, behavioral changes among marine life due to food offerings, animal harassment, trash and debris production. There are also influences resulting from the traffic and anchoring of vessels and exceeding the carrying capacity of dive sites - little known in most conservation areas.

Reef environments in Brazil are distributed from the northeast coast to Espírito Santo and are the only reef ecosystems in the South Atlantic (Maida \& Ferreira, 1997). These environments are important sources of food, tourism potential and income for coastal populations, in addition to providing protection from wave impact on several beaches in the region. Parallel to the Rio Grande 
do Norte state coastline are the reefs of Maracajaú. This reef complex inserted within an environmental protection area has been the target of severe pressure in recent decades, showing signs of degradation caused primarily by tourist exploitation, overfishing and disordered coastal occupation.

In order to assess the impact of tourism on Maracajaú reefs, a study was conducted based on the distribution of different seaweed species. These organisms are considered to be ideal bioindicators, since their presence, density and dominance reflect the status of natural conditions in the environment. Seaweeds were studied in two areas, one with tourist presence (beside a floating structure used as a dive base) and another where visitation is prohibited. Indices of richness, diversity and dominance for both areas were compared, as well as biomass for the most abundant species. Analysis of similarity between samples was also carried out to determine clusters formed according to the area of occurrence and abundance of species. This enabled identification of possible differences not only in specific composition for the two study areas, but also in how these species are or are not forming associations or clusters.

\section{Materials and methods}

The present study was conducted in Maracajaú $\left(5^{\circ} 24^{\prime} 40^{\prime \prime} \mathrm{S}-35^{\circ} 18^{\prime} 40^{\prime \prime} \mathrm{W}\right)$, located in Rio Grande do Norte state, Northeast Brazil. These reefs integrate the Coral Reefs Environmental Preservation Area, a conservation unit created in June, 2001. It encompasses the coastal belt and shallow ocean platform, extending over three municipalities and totaling around 33 thousand hectares of protected area. At a distance of $7 \mathrm{~km}$ from the coast, the reefs of Maracajaú occupy an area $9 \mathrm{~km}$ long and $2 \mathrm{~km}$ wide. Shallow pools of clear, warm water are visible for most of the year at low tide. Several coral species associated with marine seaweed are commonly found in this region. Artesanal and subsistence fishing are permitted along the entire reef, while recreational diving is only allowed in part of the area.

Two collection sites were established for the investigation (mean depth of $2.5 \mathrm{~m}$ ). One corresponded to a region where tourist activity is not allowed (A1), while the other was $800 \mathrm{~m}$ from the first and subject to intense tourism (A2). Proximity between the areas is expected to minimize the environmental gradient, so that the main factor acting differently on seaweeds is the practice of recreational diving and all related impacts (physical contact and trampling by visitors, vessel traffic, motor oil and sediment resuspension). The size of the reef formation was also taken into account when selecting sampling sites, in addition to the direction of currents, type of sea bottom and distance between the sampling sites and support base (an anchored floating structure) used to receive tourists.

At each sampling location, seaweed biomass was measured monthly from April to September, 2005, using a $25 \times 25 \mathrm{~cm}$ square (five repetitions) placed randomly along a $10 \mathrm{~m}$ transect. All material collected was placed in labeled bags and stored in containers of seawater until arrival at the laboratory, where the seaweed was examined, identified and weighed. The nomenclature and classification system used followed Wynne (2011). Voucher material is deposited in the Macroalgae Laboratory collection of the Department of Oceanography and Limnology of the Federal University of Rio Grande of Norte.

Biomass for each taxon was determined separately every month. The structure of the seaweed community was analyzed through its taxonomic composition, species richness, the Shannon Wiener diversity index and Simpson's index of dominance, and these indicators compared between the two collection sites. The significance of the differences was tested using the t-test and variance was assessed by ANOVA (oneway). Both were applied with Statistica 6.0 software $\left(\right.$ StatSoft $^{\circledR}$, 1998). Cluster analysis was applied using the Bray-Curtis similarity index in order to determine clusters formed according to the area of occurrence. This enabled the identification of possible differences between specific compositions for both study areas. The proposed dendrograms were compiled with the Primer statistics package 5.0 (Plymouth Routines In Multivariate Ecological Research).

\section{Results and Discussion}

A total of 53 taxa, consisting of 5 Chlorophyta, 13 Ochrophyta and 35 Rhodophyta, were identified at the two sites sampled during this study. The selected study areas exhibited differences in specific composition, species occurrence frequency, biomass, diversity and dominance indices. The number of species presented little difference among sample sites, the highest found at A1 (48) and the lowest at A2 (42) (Figure 1a). Among the collected species, $71.7 \%$ were common to both areas, $20.8 \%$ were only present in A1 and $7.6 \%$ in A2. The highest number of species recorded was for Dictyotaceae and Corallinaceae in A1 and Rhodomelaceae and Dictyotaceae in A2.

Biomass was significantly different between the sites $(p<0.05)$. As expected, the largest values were recorded in A1 and the lowest in A2 (Figure 1b). The means for the study period were 237.78 \pm 65.63 and $118.02 \pm 59.14 \mathrm{~g}$ dry weight for A1 and A2, respectively. A1 showed predominance of brown seaweed species from the order Fucales and Dictyotales (mainly Sargassum hystrix J. Agardh and Dictyopteris delicatula J.V. Lamouroux). Other seaweed groups found in the flora at this site showed 
similar biomass values, indicating no notable dominance of any particular species. In contrast, the dominance of Caulerpa racemosa (Forsskål) J. Agardh over other seaweed species in the community was observed in A2. In addition to $C$. racemosa, a large extension of turf algae was observed in this area throughout the study period.

The greatest diversity was seen in A1 (Figure 1c). This is likely due to habitat complexity, since the area is protected from tourist activity. In general, increased complexity of an environment generates higher numbers of distinct niches and, consequently, allows greater species coexistence (Dean \& Connel, 1987). In contrast, in A2, which suffered the impact of tourists and all its consequences, including trampling and sediment resuspension, dominance was higher (Figure 1d). Frequent disturbance at this site caused by human presence lowers the attachment capacity of spores and prevents seaweeds from fully developing. Ecological imbalance in this location favors the presence of annual seaweeds with short life cycles, as well as that of the opportunistic C. racemosa.

Another result demonstrating differences between the two sites was the dendrogram based on similarity analysis illustrating a division into two large, distinct clusters (Figure 2). Samples from area A1 were predominant in group 1 (G1), where brown seaweeds were more notable. According to previous investigations (Hughes, 1994; Szmant, 2001), the preponderance of foliose seaweed is more evident in locations with lesser pressure of herbivores. In this sense, the "top-down" hypothesis contends that significant declines in herbivores, such as herbivorous fish, are primarily responsible for increased algal abundance (Hughes, 1994; Gardner et al., 2003).

Group 2 showed greater species representation at site A2 and formed the three well-defined subgroups discussed below. The isolated element in the center of the dendrogram (G3) corresponds to a subsample collected in September in the impacted area, consisting exclusively of the red seaweed Gelidiella acerosa (Forssk.) Feldmann \& Hamel.

The three subgroups formed by the cluster analysis are a reflection of the three types of associations identified in A2, categorized in accordance with biological composition. The first association consisted of articulated coralline algae (Jania adhaerens J.V. Lamour., Amphiroa beauvoisii J.V. Lamour., Amphiroa anastomosans Weber Bosse), forming extensive banks with cortical (Hypnea spinella (C. Agardh) Kütz., Laurencia catarinensis Cord.-Mar \& M.T. Fujii, Gelidiopsis planicaulis (W.R. Taylor) W.R. Taylor, Lomentaria corallicola Børgesenand Chondria dangaerdii E.Y. Dawson) and filamentous epiphyte algae (Ceramium dawsonii A.B. Joly, C. flaccidum (Kütz.) Ardiss., Neosiphonia gorgoniae (Harv.) S.M. Guim. \& M.T. Fujii). A second association was made up of Pterocladiella caerulensces (Kütz.) Sant. \& Homm., G. planicaulis and their epiphytes (mainly Ceramium dawsonii, C. vagans P.C. Silva and N. gorgoniae). The third consisted of Gelidiella ligulata E.Y. Dawson and epiphytes (primarily $C$. dawsonii). In general, these associations involved small algae with short life cycles (a)

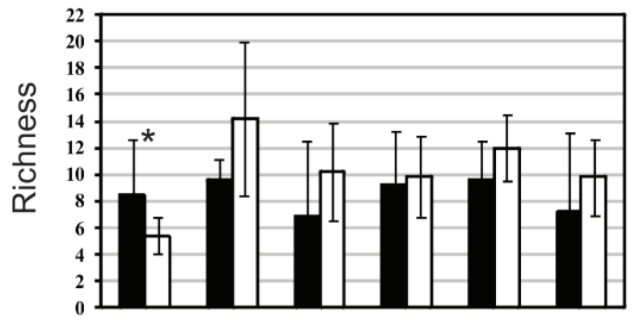

(c)

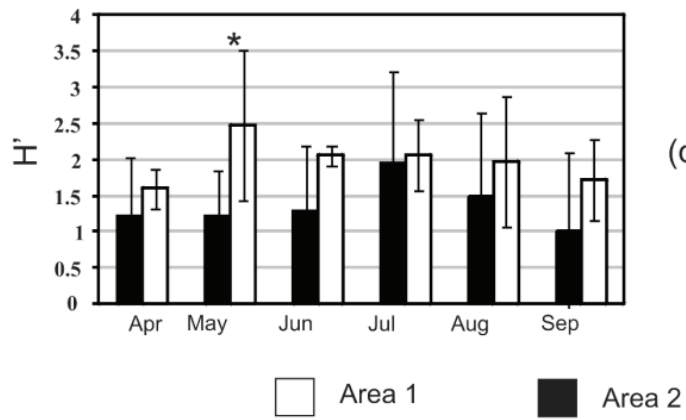

(b)

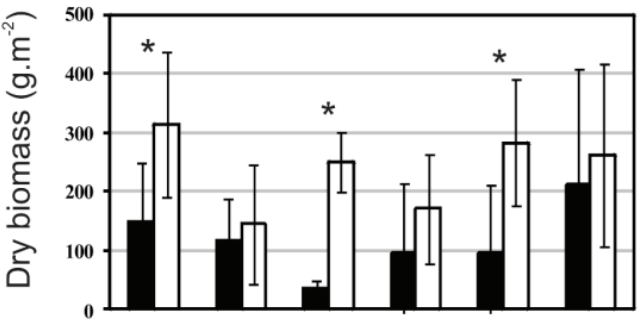

(d)

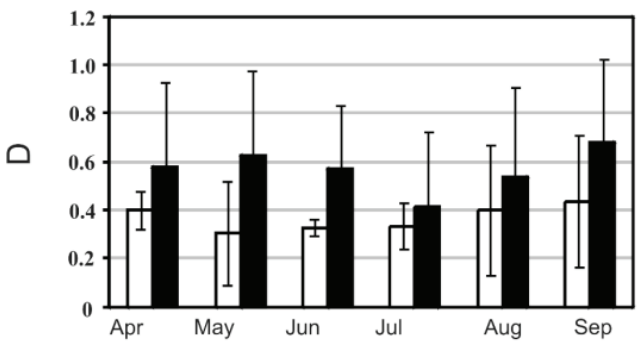

I Standard deviation

Figure 1. Estimates of the means $\pm \mathrm{SD}$ for (a) number of species (S), (b) biomass, (c) Shannon-Hill diversity (H') and (d) Simpson dominance (D), forsites A1 and A2 during April to September, 2005. The symbol * indicates a significant difference $(p<0.05, t$-test $)$. Area 1 corresponds to the sample site where tourist activity is not allowed and Area 2 to the sample site where tourist activities are allowed. 


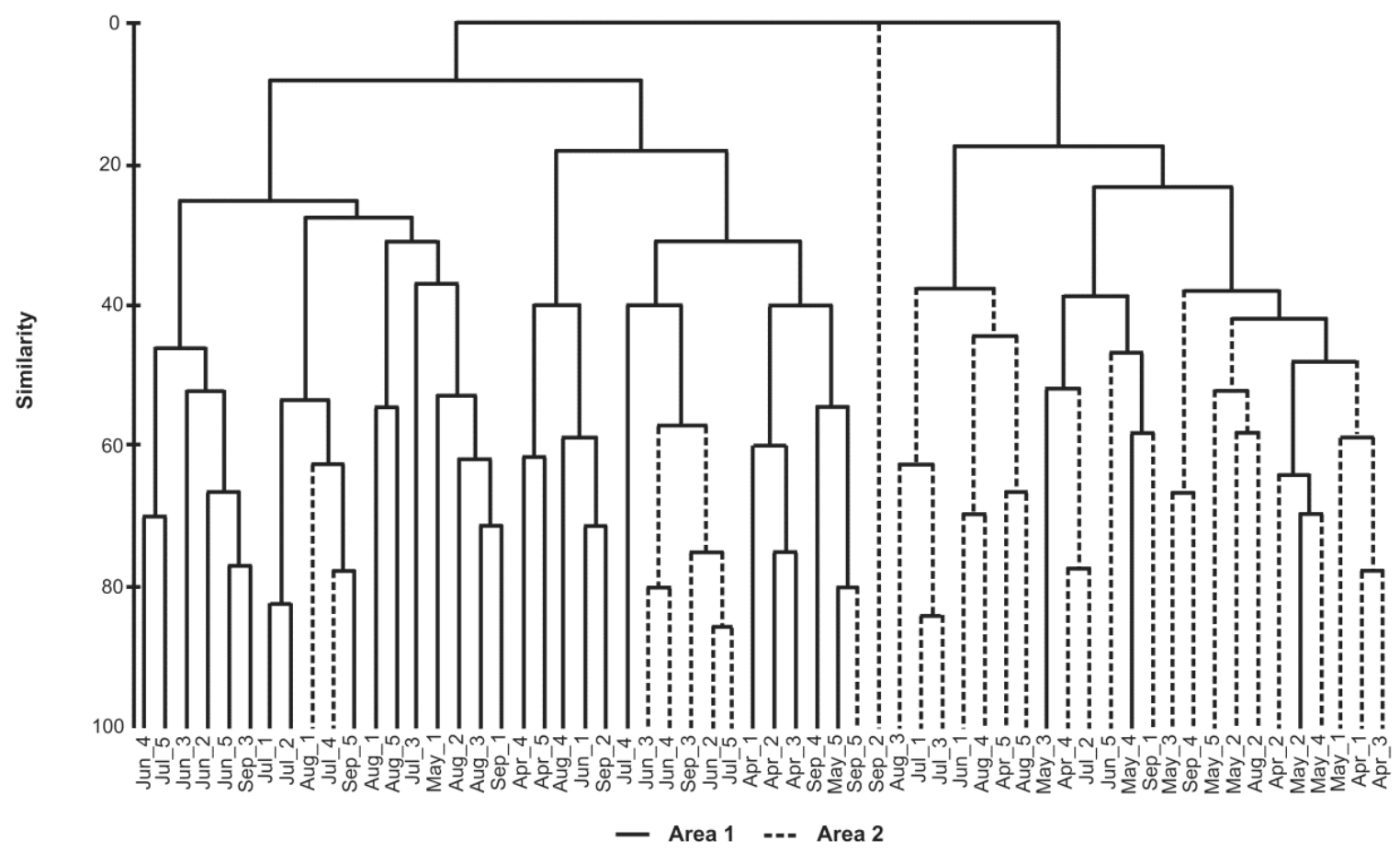

Figure 2. Similarity dendogram of quadrants based on the Bray-Curtis similarity index. Numbers following the abbreviations of the months indicate the quadrant number sampled from April to September, 2005. Area 1 corresponds to the sample site where tourist activity is not allowed and Area 2 to the sample site where tourist activities are allowed.

that can easily adapt to environments subject to frequent disruption (Kendrick, 1991; Semple, 1997; Soltan et al., 2001).

In addition to natural troubles, macroalgae communities are exposed to anthropogenic disturbances. Indeed, in the site frequently visited by tourists (A2), direct impacts include the effects of trampling and damage caused by vessels, including anchoring, propeller damage and chemical damage from release of petrochemicals and oil. This may have resulted in a shift in coverage in which turf algal species and $C$. racemosa became the dominant algae.

The present study shows that the seaweed communities are substantially different in the two areas sampled. As expected, the site without tourist presence exhibited greater species diversity, while the algal community in the area frequently visited by tourists was composed of small algae with short life cycles that easily adapt to frequently disturbed environments. These characteristics are a clear indication of degradation in the reef area subject to intense tourist activity. The results obtained in this study on the Maracajau reefs call for a serious discussion of the need for appropriate conservation this environment.

\section{Acknowledgments}

This study was supported by the CNPq and CAPES.The authors thank Estevão Martins, Vanessa Benigno, Marcelo Zigmond and the local dive operators for support in the field.

\section{References}

Bryant D, Burke L, McManus J, Spalding M 1998. Reefs at risk: a map-based indicator of potential threats to the world's coral reefs. Washington: Copyright.

Dean RL, Connell JH 1987. Marine invertebrates in algal succession. I. Variations in abundance and diversity with succession. J Exp Mar Biol Ecol 109: 195-215.

Gardner TA, Côte IM, Gill JA, Grant A, Watkinson AR 2003. Long-term region-wide declines in Caribbean corals. Science 301: 958-960.

Hughes TP 1994. Catastrophes, phase shifts, and large-scale degradation of a Caribbean Coral Reef. Science 265: 1547-1551.

Kendrick GA 1991. Recruitment of coralline crusts and filamentous turf algae in the Galapagos archipelago: effect of simulated scour, erosion and accretion. $J$ Exp Mar Biol Ecol 147: 47-63. 
Influence of tourist activity on the diversity of seaweed from reefs in

Maida M, Ferreira BP 1997. Coral reefs of Brazil: an overview. Proc $8^{\text {th }}$ Coral Reef Sym 1: 263-274.

McCook LJ 1999. Macroalgae, Nutrients and phase shifts on coral reefs: scientific issues and management consequences for the Great Barrier Reef. Coral Reefs 18: 357-367.

Petraitis PS, Dudgeon SR 2004. Detection of alternative stable states in marine communities. J Exp Mar Biol Ecol 300: 343-371.

Pickett STA, White PS 1985. The ecology of natural disturbance and patch dynamics. Orlando: Academic Press.

Semple K 1997. Biodegradation of phenols by a eukaryotic alga. Res Microbiol 148: 365-367.

Soltan D, Verlaque M, Boudouresque CF, Francour P 2001. Changes in macroalgal commuties in the vicinity of a Mediterranean sewage outfall after the setting up of a treatment plant. Mar Pollut Bull 42: 59-70.
Sousa WP 1984. The role of disturbance in natural communities. Annu Rev Ecol Syst 15: 353-391.

Szmant AM 2001. Why are coral reefs world-wide becoming overgrown by algae? 'Algae, algae everywhere, and nowhere a bite to eat!' Coral Reefs 19: 199-302.

Wynne MJ 2011. A checklist of marine benthic algae of tropical and subtropical Western Atlantic: third revision. Nova Hedwigia 140: 1-166.

\section{*Correspondence}

Eliane Marinho-Soriano

Departamento de Oceanografia e Limnologia, Universidade Federal do Rio Grande do Norte

Praia de Mãe Luiza, s/n, 59014-100 Natal-RN, Brazil

eliane@ufrnet.br

Tel.: +558433424950

Fax: +558434234951 